University of San Diego

Digital USD

Spring 5-22-2017

\title{
The Effect of Integration: A Study on the Impact of Diversity on Economic Indicators
}

Luke H. Schleier

University of San Diego

Follow this and additional works at: https://digital.sandiego.edu/honors_theses

Part of the Econometrics Commons, Macroeconomics Commons, and the Other Economics Commons

\section{Digital USD Citation}

Schleier, Luke H., "The Effect of Integration: A Study on the Impact of Diversity on Economic Indicators" (2017). Undergraduate Honors Theses. 33.

https://digital.sandiego.edu/honors_theses/33

This Undergraduate Honors Thesis is brought to you for free and open access by the Theses and Dissertations at Digital USD. It has been accepted for inclusion in Undergraduate Honors Theses by an authorized administrator of Digital USD. For more information, please contact digital@sandiego.edu. 
The Effect of Integration:

A Study on the Impact of Diversity on Economic Indicators

\author{
A Thesis \\ Presented to \\ The Faculty and the Honors Program \\ Of the University of San Diego
}

\author{
By \\ Luke Harrison Schleier \\ Economics
}

2017 


\begin{abstract}
This paper examines the effect of diversity, measured by the dissimilarity index, on the economic strength of an area. Economic strength is measured using five economic indicators: median home value, median income, median gross rent, percentage of people with health insurance, and firms per capita. The work aims to show that there is a positive economic impact due to integrating and creating communities that are more diverse. Previous work show there is a positive impact of diversity on economic indicators such as wages, rents, and production but previous studies do not look at the effect on these economic indicators. This study looks at 1,246 cities across the United States and the District of Columbia in 2015 and measures the effect of diversity on economic strength using an ordinary least squares (OLS) regression. The paper finds that there are varying degrees of significance depending on the economic indicator and racial group.
\end{abstract}




\section{Introduction}

The United States has always been a beacon to the world as on opportunity for the “American Dream" causing mass immigration during the country's relatively short history. This large amount immigration has caused the U.S. to become a nation full of varying cultures and ethnic/racial groups. As time passed in the U.S. these immigrant communities have become the racial and cultural groups that make up the modern American society. The current climate of relations between different racial groups is complicated. Although the country made large strides towards integration in the 1960s with legal cases like Brown v. Board of Education, the current interaction between racial groups seems to point to a society that is more segregated than integrated. We can see this through the rise of groups such as Black Lives Matter where one racial group has called to attention the disparate treatment they believe they are receiving from different groups. Overall, there is evidence that points to the country being both segregated and integrated, but it is important to note that there are relevant impacts due to these factors.

Regardless of whether the country is becoming more or less integrated, there are clear negative effects to the increase of segregation. There have been a number of studies that have looked at the social effects of racial segregation. Cutler and Glaeser (1997) found that if segregation was increased by $10 \%$ you would see the following effects: a $4.9 \%$ increase in the dropout rate in high school, a 8.8\% increase in idleness (here defined as not in school, working, or looking for work), and a 3.0\% increase in single motherhood. These effects were shown the disparately effect young black people more than any other racial group. An important piece to this study is that the young people that are used in this study that live in these highly segregated areas have few, if any, contact with successful role models. This is important because they have 
no frame of reference of what an educated and successful person looks like and this causes them to be less likely to become educated and successful themselves.

Another negative effect that arises due to an increase in racial segregation is the rise of spatial mismatch. Spatial mismatch derives from the idea that location is an important factor into the labor market of an urban location. Spatial mismatch arises when the bulk of low-skilled labor is located in one area, usually the central city, downtown area, and the demand for low-skilled labor is in a completely different area, usually the suburbs or outer city. This causes difficulties to arise for these low-skilled workers to acquire and maintain a job as there are many factors working against them. For instance, most public transportation is not set-up to do the central city to suburb commute at the times these workers would need to and furthermore many of these lowskilled workers are also low-income and this means they do not have sufficient funds to afford an automobile to get them from their housing location to work.

There are many reasons that a particular area may see segregation across racial lines. The first is that there are differences of incomes between racial groups. These variations in incomes cause only certain income groups and racial groups to live in particular areas. This leads to segregation across both income and racial lines. Most of the time low income housing is located in central cities causing many lower income individuals to be located there as they have very limited options for affordable housing (Mills and Lubuele, 1977). Until recently, the federal government's housing policy has actually indirectly encouraged segregation. In the past, most public housing was created in central cities and low-income areas and when the government gave individuals housing vouchers they could only be used in the city where the individual is from. Only recently has the government allowed the vouchers to become portable and to be used in suburban housing developments. 
Another reason segregation arises is the practice of exclusionary zoning. This is frequently used by areas with affluent residents that do not want affordable housing to be built in their area. They use zoning regulations to halt any construction of affordable housing. For example, a suburban government can have requirements for any new dwellings built in their area such as requiring two-car garages or even they can implement high development fees to dissuade the building of these affordable housing units. A related factor to explain racial segregation is the racial discrimination found in the housing market. The main technique used by brokers is racial steering in which they will direct certain buyers away from predominately white neighborhoods based on their race. Yinger (1998) found that when comparing two identical buyers, one white and one black, the black buyer was shown fewer dwellings, steered to particular neighborhoods, and given less advice on how to navigate the financial aspects of buying a home. The study also found that 1 in 10 black renters is denied access to housing made available to white renters, and 1 in 4 learns about fewer dwellings.

This paper will examine whether the diversity of an area is a determinant of the economic strength of that particular area. The measure of diversity that will be used is the Dissimilarity Index which indicates the level of diversity in area by determining what percentage of different racial groups would have to be displaced in order for all neighborhoods within a city to be proportionally equal across all neighborhoods. The paper will focus on the racial populations of Black, Hispanic, Asian, American Indian, and Native Hawaiian in cities in the United States and The District of Columbia. The previously mentioned racial groups are compared to the White population in each city, and given a value which then determines how integrated or segregated the cities are compared to other cities. 
The paper will define economic strength by the performance of five economic indicators. The five economic indicators will split into three subheading groups to define them: incomebased indicators, social indicator, and business-related indicator. The income based indicators are median income, median household value, and median gross rent which is calculated by landlords by taking the total yearly rent payment minus any expenses for they year. The social indicator is the percentage of citizens with health insurance within the city. The business-related indicator is firms per capita which is calculated by taking all firms (businesses) within a city and diving it by the population of that city. Cities that will are determined to be economically strong are cities that have high median incomes, high median home values, high gross rent, a high percentage of citizens with health insurance, and a large number of firms per capita.

Diversity is an important factor to study as it ties into many economic theories. First, more diverse areas lead to the variety of skills and labor. According to Ottaviano and Peri (2006) this diversity of labor leads to workers having heterogeneous sets of skills determined from their country of origin or cultural background. The diversification of skills leads to many economic benefits including the sharing of ideas that leads to higher creativity and innovation, matching qualified labor to jobs that meet their skill sets, and meeting the needs of a global economy in terms of understanding new markets.

This paper will present a new argument to previous research on diversity and economics. The main argument behind the paper is the presence of cultural diversity within an area represents a classic positive externality story. An externality within economics occurs when the actions or inactions of one party leads to either positive or negative effect, often called spillover benefits or spillover costs, on a party that is not directly involved in the action. For this paper, the author will argue that the increase of cultural diversity leads to spillover benefits to member of 
other racial groups from the group that has their population increased. This is best explained by the following graph:

\section{Diversity as an Externality}

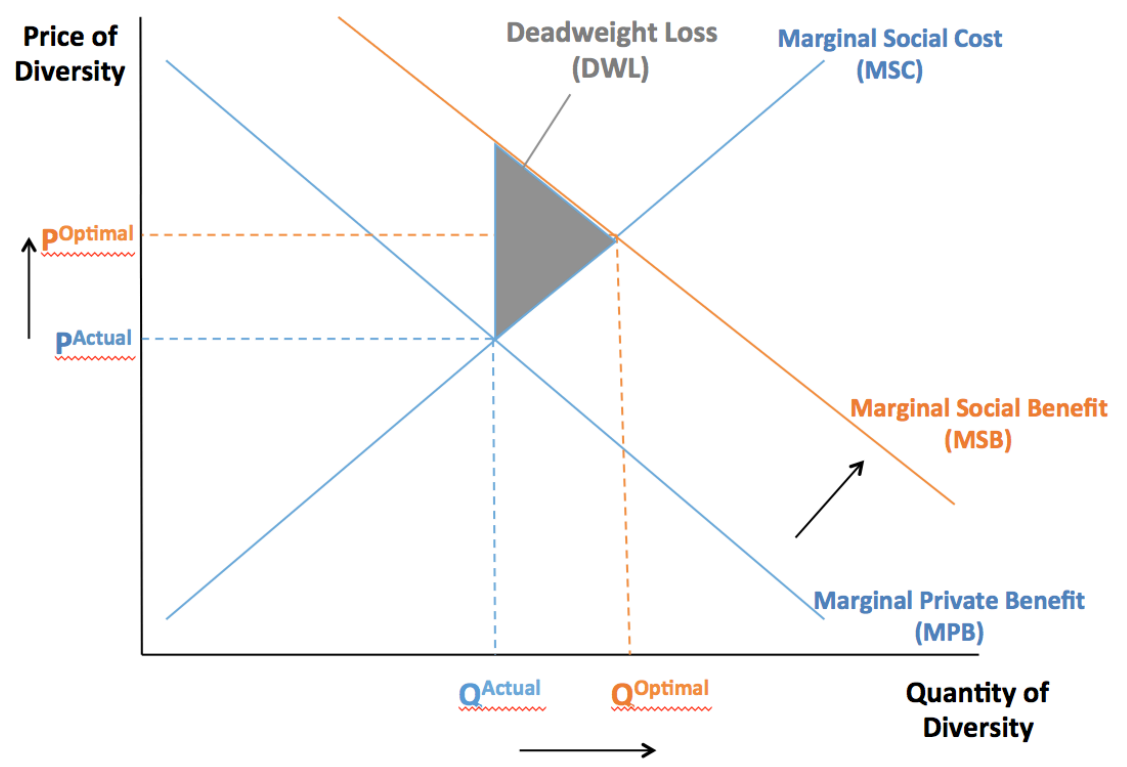

A model of a positive externality is represented in the graph above. On the y-axis is the Price of Diversity and on the x-axis is the Quantity of Diversity. In a normal market we would expect the efficient price and quantity to be represented by where the Marginal Private Benefit, the benefit received from increasing diversity one more unit, and the Marginal Social Cost, the cost to increase diversity by one more unit, intersect. These values are represented by P-actual and Q-actual, the price and quantity that actually occur within the market. This is how the market would function without the presence of an externality but if there is an externality it with effects the benefits or costs within the market. There is an increase in the benefits associated with diversity due to the positive externality. The shifts the benefit line in the graph up and to the right 
and becomes the new line which will be called the Marginal Social Benefit. The new efficient values for the market are represented by P-optimal and Q-optimal. This is key because even though there is an externality in the market we are still producing at P-actual and Q-actual as we do not recognize that there is this externality. This causes there to be a loss to society, which is represented by the shaded triangle and labeled Deadweight Loss. This is the cost that society incurs dues to the inability to recognize the externality and can be eliminated if we produce at the optimal quantity and price. This paper aims to show evidence that this externality does exist and that the market for diversity is not producing at the efficient level.

This research is important to local, state, and federal governments in determining the legislation they enact to encourage diversity and the economic impact of those laws. The framework of the paper allows for analyzing each racial group as there is a Dissimilarity Index value for each racial group. This is helpful to note if there is a specific racial group that legislation should target to help increase economic strength across cities.

The research looks at 1,246 cities across the United States and the District of Columbia.. Contrary to theory and the previous literature of Ottaviano and Peri (2006), and Malizia and Ke (1993) this study finds that diversity has varied effects on the economic strength of a city.

\section{Literature Review}

The literature on diversity and segregation in both economic and other academic fields is extensive. Most of the literature links diversity to living in an urban area and much of the research is focused around the effects on these urban areas due to more or less diverse areas. Some of the research studies certain ethnic and racial groups and how an increase in these 
populations affects the economy. Most of the research finds positive effects on different economic indicators due to an increase in diversity.

White (1983) finds that the dissimilarity index is one key measure of diversity in an area. It is especially useful to look at diversity and segregation by race in residential areas as that is where we saw many of the reasons for segregation arising. His findings are key for further research across large urban areas but notes that when looking across many urban areas the dissimilarity index is superior to other measures of segregation as it a clearer and more concise way to measure diversity in metropolitan statistical area level data.

When looking at diversity and how it effects a country as a whole Montalvo and ReynalQuerol (2005) find that higher ethnolinguistic fractionalization, segregation based on ethnic characteristics like race or religion, in a developing country has negative effects on growth of GDP. They specifically find that the negative effect on growth of GDP is due to a large decrease in the rate of investment in the country but increases public consumption of goods..

Instead of looking at a large area like a country as seen in Montalvo and Reynal-Querol (2005) both Ottaviano and Peri (2006) and Malizia and Ke (1993) focus on metropolitan areas. They find positive economic results due to an increase in the diversity of the metropolitan area. In particular Ottaviano and Peri (2006) examine wages and rents in cities with large and small immigrant populations. They make the assumption that immigrant workers enter into the economy with a diverse set of skills, which adds efficiency to the labor force. By contrast previous studies (White, 1983; Malizia and Ke, 1993) assumed that immigrant workers enter the labor force with a homogeneous set of skills that only allowed them to have relatively lowskilled jobs. With their specific assumption Ottaviano and Peri (2006) find that higher wages and higher rents are statistically correlated with greater diversity in a given area. They also find that 
areas with greater diversity also have a strong correlation with increases in efficiency of worker's output of not only immigrant workers but also native-born workers.

Similarly, Malizia and Ke (2005) find results supporting the correlation between high diversity and strong economic performance. They also look at metropolitan areas across the US and use particular macroeconomic variables such as unemployment, growth rate, and employment in industries with high employee turnover and noneconomic variables like population. The results show that cities with higher diversity are correlated with lower unemployment and more stability of reactions to economic slumps than cities with less diversity. Malizia and Ke's findings add support to the hypothesis of strong economic performance in production, employment, and efficiency in areas with higher diversity.

Looking specifically at urban areas, Musterd (2006) studies the effect of a culturally diverse city, one with large immigrant populations from varying areas of the world, on the creative economy. He shows that cities that are culturally diverse tend to be large metropolitan areas that attract different types of businesses. He finds that labor with creative skill sets have a preference for large metropolitan areas. These areas are defined by cultural and social diversity that plays an integral role into the rate and level of creativity.

On the other hand, Baldwin and Huber (2010) take a different approach and look at diversity and the amount of public good provisions. They argue that the amount of public good provisions in an area is a good indicator of a strong economy in terms of production and consumption. So, the more public goods an area has the more economically stable the firms are in relation to the amount of production and consumption. Baldwin and Huber (2010) show that the more diverse an area the less likely the area is to have public goods. This is true for both ethnic and economic diversity. 
Overall, previous research shows a relationship between high diversity and generally strong economic performance for production, consumption, efficiency, and employment. This paper will seek to study another indicator of economic performance, median income, and how it differs in areas with varying levels of diversity determined by the dissimilarity index. The outcome of the research will find significance in diversity's effect on the chosen economic indicators, but it will be tough to determine of diversity has a meaningful impact on economic strength. Moreover, this research will help policy makers determine necessary steps to create more diverse populations to increase economic performance in given areas.

\section{Empirical Framework}

\section{i) Empirical Methodology}

The median income, median home value, median gross rent, percentage of people with health insurance, and firms per capita of 1,246 cities across the United States and the District of Columbia in 2015 are analyzed using and Ordinary Least Squares (OLS) regression. The five OLS regression equations are as follows, with the first six independent variables representing the Dissimilarity Indices of that particular city:

(1) $\operatorname{lnMedHome}_{i}=\beta_{0}+\beta_{1} \mathrm{diB}_{\mathrm{i}}+\beta_{2} \mathrm{diAI}_{\mathrm{i}}+\beta_{3} \mathrm{diA}_{\mathrm{i}}+\beta_{4} \mathrm{diNH}_{\mathrm{i}}+\beta_{5} \mathrm{diH}_{\mathrm{i}}+\beta_{6} \mathrm{diO}_{\mathrm{i}}+\beta_{7} \operatorname{lnPop}_{\mathrm{i}}+$

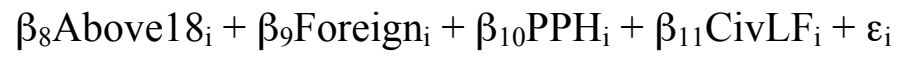

(2) $\operatorname{lnMedInc}_{\mathrm{i}}=\beta_{0}+\beta_{1} \mathrm{diB}_{\mathrm{i}}+\beta_{2} \mathrm{diAI}_{\mathrm{i}}+\beta_{3} \mathrm{diA}_{\mathrm{i}}+\beta_{4} \mathrm{diNH}_{\mathrm{i}}+\beta_{5} \mathrm{diH}_{\mathrm{i}}+\beta_{6} \mathrm{diO}_{\mathrm{i}}+\beta_{7} \operatorname{lnPop} \mathrm{p}_{\mathrm{i}}+$

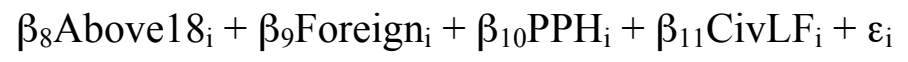


(3) MedRent $_{i}=\beta_{0}+\beta_{1} \operatorname{diB}_{\mathrm{i}}+\beta_{2} \mathrm{diAI}_{\mathrm{i}}+\beta_{3} \mathrm{diA}_{\mathrm{i}}+\beta_{4} \mathrm{diNH}_{\mathrm{i}}+\beta_{5} \mathrm{diH}_{\mathrm{i}}+\beta_{6} \mathrm{diO}_{\mathrm{i}}+\beta_{7} \operatorname{lnPop}_{\mathrm{i}}+$

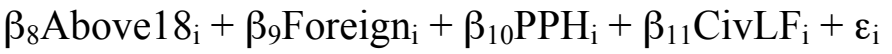

(4) HealthInsur ${ }_{i}=\beta_{0}+\beta_{1} \operatorname{diB}_{\mathrm{i}}+\beta_{2} \mathrm{diAI}_{i}+\beta_{3} \operatorname{diA}_{\mathrm{i}}+\beta_{4} \mathrm{diNH}_{\mathrm{i}}+\beta_{5} \mathrm{diH}_{\mathrm{i}}+\beta_{6} \mathrm{diO}_{\mathrm{i}}+\beta_{7} \operatorname{lnPop}_{\mathrm{i}}+$

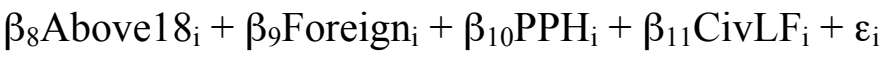

${ }_{(5)}$ FirmsCap $_{i}=\beta_{0}+\beta_{1} \operatorname{diB}_{i}+\beta_{2} \mathrm{diAI}_{i}+\beta_{3} \mathrm{diA}_{\mathrm{i}}+\beta_{4} \mathrm{diNH}_{\mathrm{i}}+\beta_{5} \mathrm{diH}_{\mathrm{i}}+\beta_{6} \mathrm{diO}_{\mathrm{i}}+\beta_{7} \operatorname{lnPop}_{\mathrm{i}}+$

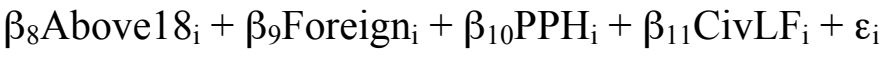

Descriptions of all variables as well their sources can be found in Table 1. Building on Ottaviano and Peri (2006) which focuses on wages and rents but studies diversity within a city this study uses median income as an economic indicator as it gives a broad range of values and allows for the effect of diversity to become present..

The dissimilarity index is included to measure the level of diversity in a city. The dissimilarity index is the most commonly used measure of segregation between two groups, reflecting their relative distributions across neighborhoods within the same city. The dissimilarity index varies between 0 and 100, and measures the percentage of one group that would have to move across neighborhoods to be distributed the same way as the second group. A dissimilarity index of 0 indicates conditions of total integration under which both groups are distributed in the same proportions across all neighborhoods. A dissimilarity index of 100 indicates conditions of total segregation such that the members of one group are located in completely different neighborhoods than the second group. Neither extreme value is generally found in most cities 
and metropolitan areas; rather the value typically lies somewhere in-between 0 and 100 . The calculation of the index for an area to account for the black population is given by the following:

$$
\frac{1}{2} \sum_{i=1}^{N}\left|\frac{b_{i}}{B}-\frac{w_{i}}{W}\right|
$$

Where $b_{i}$ is the population of black persons in neighborhood, $i, B$ is the population of black persons in the particular city, $\mathrm{w}_{\mathrm{i}}$ is the population of white persons in the neighborhood, $\mathrm{i}, \mathrm{W}$ is the population of white persons in the whole city, and $\mathrm{N}$ is the number of neighborhoods within the city.

A city's median income, median home value, median gross rent, percentage of people with health insurance, and firms per capita are hypothesized to be greater in areas with dissimilarity indices closer to zero meaning areas with more diverse populations. The results from previous research point to higher diversity meaning better performing economic indicators such as wages and rents in Ottaviano and Peri (2006) or unemployment and stability in Malizia and Ke (1993).

Other independent variables are centered on demographic characteristics of a city including population of the city, percentage of foreign-born persons, person per household, and percentage of people in the labor force. All of these were determined to be important economic indicators in Malizia and Ke (1993).

\section{ii) Data and Descriptive Statistics}

The data for this research is comprised of 1,246 cities across the United States and the District of Columbia in the year 2015. Table 1 provides the variable definitions from the regression models and their sources. Table 2 shows the descriptive statistics for the variables of the OLS equation. 
The natural log of median home values ranges from 10.392 to 14.414 with a mean of 12.172 . The city with the highest median home value is Los Altos, California $(\$ 1,819,300)$ and the lowest is Flint, Michigan $(\$ 32,600)$. The natural log of median incomes ranges from 9.879 to 12.078 with a mean of 10.973 . The city with the highest median income is Los Altos, California $(\$ 175,938)$ and the city with the lowest is $(\$ 19,526)$. Median gross rent has a range of $\$ 541$ to $\$ 2,700$ with a mean of $\$ 1,013.25$. The city with the highest median gross rent is Saratoga, California (\$2,700) and the city with the lowest is East St. Louis, Illinois (\$541). The percentage of people with health insurance has a range of $57.8 \%$ to $98.2 \%$ with a mean of $85.094 \%$. The city with the highest percentage of people with health insurance is Los Altos, California (98.2\%) and the city with the lowest is San Juan, Texas (57.8\%). The number of firms per capita has a range from .033 to .451 with a mean of .095 . The city with highest number of firms per capita is Beverley Hills, California (.451) and the city with the lowest is North Chicago, Illinois (.033).

Tables 3.1-3.5 show the correlation matrices for all of the variables. These tables are used to determine if there is any presence of multicollinearity in the regression equations meaning that one or more of the dependent variables explain the same differences in the independent variables. This is important because if there is multicollinearity within any of the regression equations it can lead to incorrect beta coefficients being predicted and the results to be incorrect and biased. We use the correlation matrix to look for any values that are highly correlated with each other, signaling that they are representing the same explanatory power. The threshold used in this paper is anything with a .700 correlation or higher. If any two variables were above the .700 threshold, the regression model would have to be changed by dropping one of the variables to avoid having biased results. The highest correlation found in any of the tables is between the Dissimilarity Index of American Indian and the Dissimilarity Index of Native Hawaiians (.603) but is not high 
enough for either to be dropped. Although there is a high correlation, the author is confident that this will not affect the results as it is below the threshold and the two variables are needed within the regression in order to explain each racial group's effect on the independent variable.

The other potential problem that can arise in OLS regression equations is heteroscedasticity. Heteroscedasticity occurs when the dependent variable is correlated with the error term. This, like multicollinearity can affect the regression results and cause them to be biased. To check to see if the regression has heteroscedastic error the Breusch-Pagan test was run. The Breush-Pagan test showed that there was not heteroscedasticity present in any of the models.

\section{Empirical Results}

This paper aims to determine if racial integration, meaning a more diverse area, has an effect on the economic strength of a city in the U.S. The hypothesis for the research is that a more diverse population will be associated with a strong economy meaning that a city has a high median home value, a high median income, a high median gross rent, a high percentage of people with health insurance, and a large number of firms per capita. Using an ordinary least squares regression, the diversity variables were regressed against the five economic indicators to determine the significance and effect of the variables. When interpreting the results of the five regression equations the study finds varying results. To support the hypothesis, the coefficients of the diversity variables would need to be significant and negative as the higher the Dissimilarity Index the more segregated the city is.

The full results of the regression equations are shown in tables 4.1-4.5. The following paragraphs will highlight the results of the diversity variables and explain their effect on the studied economic indicator. 
The results of regression 1 are shown in table 4.1 and shows the results of the median home value regression equation. The overall regression is significant at the $1 \%$ level as shown by the f- statistic having a p-value of 0.000 . This means the regression has overall significance so the results of the interpretable and correct. The r-squared is .590 meaning that $59.0 \%$ of the variation of the natural log of median home value is explained by the independent variables. The Dissimilarity Indices for American Indian, Asian, and Native Hawaiian are significant at the 1\% level. Interesting to note in the results of the regression is that the Dissimilarity Index for American Indian is positive meaning that as the American Indian population of a city become more segregated, the median home value of that city increases. Although the three Dissimilarity Indices are significant it is important to note the interpretation of these variables. For example, we would interpret the Dissimilarity Index for Asian by saying that a 10 unit decrease in the Dissimilarity Index for Asian of a city is associated with a $.15 \%$ increase of the natural log of median home value. Note that all interpretations will use a 10 unit increase rather than the standard 1 unit increase as when the Dissimilarity Index changes it is more likely to change in large quantities (Cutler and Glaeser 1997). It may seem as though a .15\% increase is little but when fully interpreted it can actually correlate with a large increase in the median home value of a city. For example, in San Diego, California, the median home value is $\$ 463,300$ and the natural $\log$ is 13.046 , an increase of $.15 \%$ on the natural $\log$ would increase it to 13.066 . This would correlate to increase in the median home value of $\$ 9,094$ to a new median home value of $\$ 472,394$.

The results of regression 2 are shown in table 4.2 and shows the results of the median income regression equation. The overall regression is significant at the $1 \%$ level as shown by the f- statistic having a p-value of 0.000 . The r-squared is .521 meaning that $52.1 \%$ of the variation 
of the natural log of median income is explained by the independent variables. The Dissimilarity Indices for American Indian, Asian, Native Hawaiian, and Hispanic are significant at the 1\% level. Similarly to regression 1, the Dissimilarity Index for American Indian is positive meaning that as the American Indian population of a city become more segregated the higher a city's median income will be. For interpretation for this regression, a 10 unit decrease in the Dissimilarity Index of Asian of a city is associated with a $.11 \%$ increase in the natural log of median income of that city. For example, the median income for San Diego, California is $\$ 66,116$ or 11.099 in natural $\log$ terms. A .11\% increase in the natural $\log$ would result in an $\$ 801$ increase in a new median income to $\$ 66,917$.

The results of regression 3 are shown in table 4.3 and shows the results of the median gross rent regression equation. The overall regression is significant at the $1 \%$ level as shown by the f- statistic having a p-value of 0.000 . The r-squared is .560 meaning that $56.1 \%$ of the variation of the median gross rent is explained by the independent variables. The Dissimilarity Indices for American Indian, Asian, Native Hawaiian, Hispanic, and Other are significant at the $1 \%$ level. The trend continues with American Indian being positive, which is the opposite of the rest of the Dissimilarity Indices. For interpretation of this regression, a 10 unit decrease in the Dissimilarity Index of Asian of a city is associated with a $6.309 \%$ increase in the median gross rent of that city. For example, the median gross rent for San Diego, California is $\$ 1,377$. A $6.309 \%$ increase would result in the median gross rent increasing by $\$ 87$ resulting in a new median gross rent of $\$ 1,464$.

The results of regression 4 are shown in table 4.4 and shows the results of the percent of people with health insurance regression equation. The overall regression is significant at the $1 \%$ level as shown by the f- statistic having a p-value of 0.000 . The r-squared is .434 meaning that 
$43.4 \%$ of the variation of the median gross rent is explained by the independent variables. The Dissimilarity Indices for Black, American Indian, Asian, Hispanic, and Other are significant at the $1 \%$ level. The trend once again continues with American Indian being positive, which is the opposite of the rest of the Dissimilarity Indices. For interpretation of this regression, a 10 unit decrease in the Dissimilarity Index of Asian of a city is associated with a $.086 \%$ increase in the percent of people that have health insurance in that city. For example, the percentage of people with health insurance in San Diego, California is $84.3 \%$. A $0.86 \%$ increase would result in the percentage of people with health insurance increasing by $.72 \%$ to a new percentage of people with health care of $85.02 \%$.

The results of regression 5 are shown in table 4.5 and shows the results of the firms per capita regression equation. The overall regression is significant at the $1 \%$ level as shown by the f- statistic having a p-value of 0.000 . The r-squared is .865 meaning that $86.5 \%$ of the variation of the firms per capita is explained by the independent variables. The Dissimilarity Indices for Black, American Indian, Asian, and Hispanic are significant at the $1 \%$ level. Again we see the trend continues with American Indian being positive, which is the opposite of the rest of the Dissimilarity Indices. For interpretation of this regression, a 10 unit decrease in the Dissimilarity Index of Asian of a city is associated with a $.004 \%$ increase in the firms per capita of that city. For example, the firms per capita for San Diego, California is .104. A .004\% increase would result in firms per capita increasing by .001 resulting in a new firms per capita of .105 .

Contrary to previous literature in White (1983), Ottaviano and Peri (2006) and Malizia and $\mathrm{Ke}$ (1993) some of the Dissimilarity Index variables cannot be determined to be non-zero as none of them are significant at $1 \%$ level. However, all regressions found many of the Dissimilarity Index variables to be significant and most of them were found to have a negative 
effect meaning that as segregation increased the economic indicator decreased. These results would support the hypothesis of higher economic strength in more diverse areas.

There is one surprising trend for every regression, as the Dissimilarity Index for American Indian is significant but a positive value. This result is a contradiction to the hypothesis. The main reason that the beta coefficient may have turned out positive is that it may not necessarily be the most reliable measure. Looking at many of the cities used in the study many of them have very small American Indian populations, most of the time less that $1 \%$ of the total racial breakdown. This could cause the number in the regressions to be incorrect as if there is only a few hundred American Indian individuals in a city of hundreds of thousands of people, it will be tough for them to be distributed evenly among neighborhoods.

\section{Conclusion}

The paper determines the impact of diversity on the strength of 1,246 cities in the United States and the District of Columbia. The impact is shown through OLS regression analysis using the dissimilarity index as a measure of diversity within the cities. The economic strength of a city is determined by the performance of five economic indicators: median home value, median income, median gross rent, percentage of people with health insurance, and firms per capita. The main findings suggest that diversity of many racial groups have an impact on the strength of the economy. For median home value American Indian, Asian, and Native Hawaiian are significant. For median income American Indian, Asian, Native Hawaiian, and Hispanic are significant. For median gross rent American Indian, Asian, Native Hawaiian, Hispanic, and Other are significant. For the percentage of people with health insurance Black, American Indian, Asian, Hispanic, and 
Other are significant. For firms per capita Black, American Indian, Asian, and Hispanic are significant.

If the local government is determining actions to improve economic strength of a city, it is best to look at policies targeting diversity of a city. These factors are determined to be significant when analyzing economic strength. However, it is still important to note that diversity is key to many other factors such as wages and rents as shown in Ottaviano and Peri (2006). Many policies that a government, both federal and local, could legislate can improve these factors but can also improve the diversity and even segregated populations. Offering tax breaks to charter schools in racially segregated neighborhoods, vouchers for housing in nonurban areas to lower income families, and job training programs to help workers obtain the right set of skills for the modern working environment are all ways that governments can improve housing prices, education, and striving towards full employment while trying to address the issue of diverse neighborhoods.

As far as further research on the topic, there could be further research into the effect of diversity on employment and whether areas with higher diversity experience more employment or the opposite. Diversity is quickly becoming one of the key topics in the U.S. in recent times, as the country seems to becoming increasingly segregated so research into the effects of diversity will be key to determining how the government can enact legislation to improve economic factors such as production, consumption, and employment. 


\section{References}

Baldwin, K., \& Huber, J. D. (2010). Economic versus cultural differences: Forms of ethnic diversity and public goods provision. American Political Science Review, 104(04), 644662.

CensusScope -- Racial Segregation Statistics for Cities ... (n.d.). Retrieved October 15, 2016, from http://www.censusscope.org/segregation.html

Cutler, Daved M., and Edward L. Glaeser. “Are Ghettos Good or Bad?” Quarterly Journal of Economics (1997), pp. 827-72

Malizia, E. E., \& Ke, S. (1993). The influence of economic diversity on unemployment and stability. Journal of Regional Science, 33(2), 221-235.

Mills, Edwin S., and Luan Sende Lubele, “Inner Cities.” Journal of Economic Literature 35 (1977), pp. 727-56

Montalvo, J. G., \& Reynal-Querol, M. (2005). Ethnic diversity and economic development. Journal of Development economics, 76(2), 293-323.

Musterd, S. (2006). Segregation, urban space and the resurgent city. Urban Studies, 43(8), 13251340.

Ottaviano, G. I., \& Peri, G. (2006). The economic value of cultural diversity: evidence from US cities. Journal of Economic geography, 6(1), 9-44.

White, M. J. (1983). The measurement of spatial segregation. American Journal of Sociology, 1008-1018.

United States QuickFacts from the US Census Bureau. (n.d.). Retrieved October 15, 2016, from http://www.census.gov/quickfacts/table/PST045215/00 


\section{APPENDIX}

Table 1. Data Definition and Source

\begin{tabular}{|ccc|}
\hline Variable & Definition & Source \\
\hline InMedInc & Nature log of median household income, 2015 & US Census Bureau \\
\hline InMedHome & Natural log of median home value, 2015 & US Census Bureau \\
\hline MedRent & Median gross rent, 2015 & US Census Bureau \\
\hline HealthInsur & Persons with health insurance, under 65 years, percent, 2015 & US Census Bureau \\
\hline FirmsCap & Firms per capita, 2015 & US Census Bureau \\
\hline diB & Dissimilarity Index - Black, Range 0-100 & CensusScope \\
\hline diAl & Dissimilarity Index - American Indian, Range 0-100 & CensusScope \\
\hline diA & Dissimilarity Index - Asian, Range 0-100 & CensusScope \\
\hline diNH & Dissimilarity Index - Native Hawaiian, Range 0-100 & CensusScope \\
\hline diH & Dissimilarity Index - Hispanic, Range 0-100 & CensusScope \\
\hline diO & Dissimilarity Index - Other, identified as mixed-racial, Range 0-100 & CensusScope \\
\hline InPop & Log of population, July 1, 2015 & US Census Bureau \\
\hline Above18 & Forson above 18 years percent, July 1, 2015 & US Census Bureau \\
\hline Foreign & Person per household, 2015 & US Census Bureau \\
\hline PPH & In civilian labor force, total, percent of population age 16 years+, 2015 & US Census Bureau \\
\hline CivLF & & US Census Bureau \\
\hline
\end{tabular}


Table 2. Descriptive Statistics

\begin{tabular}{|c|c|c|c|c|c|}
\hline Variable & Observations & Mean & Std. Dev. & Min & Max \\
\hline \hline InMedHome & 1,246 & 12.172 & 0.615 & 10.392 & 14.414 \\
\hline InMedInc & 1,246 & 10.873 & 0.352 & 9.879 & 12.078 \\
\hline MedRent & 1,246 & $1,013.250$ & 317.476 & 541.000 & $2,700.000$ \\
\hline HealthInsur & 1,246 & 85.094 & 6.763 & 57.800 & 98.200 \\
\hline FirmsCap & 1,246 & 0.095 & 0.034 & 0.033 & .451 \\
\hline diB & 1,246 & 42.650 & 14.909 & 8.000 & 92.400 \\
\hline diAl & 1,246 & 41.814 & 15.460 & 1.600 & 89.700 \\
\hline diA & 1,246 & 34.360 & 18.021 & 8.800 & 89.000 \\
\hline diNH & 1,246 & 68.893 & 19.012 & 7.200 & 99.900 \\
\hline diH & 1,246 & 33.810 & 12.675 & 8.200 & 77.200 \\
\hline diO & 1,246 & 54.579 & 19.650 & 7.000 & 99.800 \\
\hline InPop & 1,246 & 11.079 & 0.780 & 9.450 & 15.917 \\
\hline Above18 & 1,246 & 76.077 & 4.492 & 62.2 & 95.400 \\
\hline Foreign & 1,246 & 15.501 & 12.043 & 62.200 & 72.700 \\
\hline PPH & 1,246 & 2.664 & 0.400 & .400 & 4.520 \\
\hline CivLF & 1,246 & 64.325 & 6.071 & 36.800 & 79.300 \\
\hline
\end{tabular}


Table 3.1 Correlation Matrix Median Home Value

\begin{tabular}{|c|c|c|c|c|c|c|c|c|c|c|c|c|}
\hline & $\begin{array}{l}\text { lnMed } \\
\text { Home }\end{array}$ & $\mathrm{diB}$ & diAI & diA & diNH & diH & $\mathrm{diO}$ & $\ln$ Pop & $\begin{array}{c}\text { Above } \\
18\end{array}$ & Foreign & PPH & CivLF \\
\hline lnMedHome & 1.000 & & & & & & & & & & & \\
\hline $\mathrm{diB}$ & -.308 & 1.000 & & & & & & & & & & \\
\hline diAI & -.062 & .479 & 1.000 & & & & & & & & & \\
\hline diA & -.496 & .566 & .423 & 1.000 & & & & & & & & \\
\hline diNH & -.436 & .462 & .603 & .535 & 1.000 & & & & & & & \\
\hline $\mathrm{diH}$ & -.110 & .505 & .404 & .423 & .278 & 1.000 & & & & & & \\
\hline $\mathrm{diO}$ & -.433 & .428 & .430 & .502 & .577 & .243 & 1.000 & & & & & \\
\hline $\operatorname{lnPop}$ & .064 & .231 & -.026 & .130 & -.147 & .344 & -.135 & 1.000 & & & & \\
\hline Above18 & .161 & .119 & .095 & .010 & .095 & -.057 & -.068 & -.057 & 1.000 & & & \\
\hline Foreign & .530 & -.132 & .062 & -.209 & -.279 & .070 & -.333 & .152 & -.104 & 1.000 & & \\
\hline $\mathrm{PPH}$ & .222 & -.244 & -.129 & -.177 & -.343 & -.058 & -.170 & .076 & -.456 & .578 & 1.000 & \\
\hline CivLF & .345 & -.219 & $\begin{array}{l}.219 \\
\end{array}$ & -.250 & -.026 & -.035 & -.128 & .098 & $\begin{array}{l}.149 \\
-.149\end{array}$ & .174 & .093 & 1.000 \\
\hline
\end{tabular}

Table 3.2 Correlation Matrix Median Income

\begin{tabular}{|l|l|l|l|l|l|l|l|l|l|l|l|l|}
\hline & $\begin{array}{c}\text { lnMed } \\
\text { Inc }\end{array}$ & $\mathrm{diB}$ & $\mathrm{diAI}$ & $\mathrm{diA}$ & $\mathrm{diNH}$ & $\mathrm{diH}$ & $\mathrm{diO}$ & $\operatorname{lnPop}$ & $\begin{array}{c}\text { Above } \\
18\end{array}$ & Foreign & PPH & CivLF \\
\hline lnMedInc & 1.000 & & & & & & & & & & & \\
\hline $\mathrm{diB}$ & -.382 & 1.000 & & & & & & & & & & \\
\hline $\mathrm{diAI}$ & -.090 & .479 & 1.000 & & & & & & & & & \\
\hline $\mathrm{diA}$ & -.540 & .566 & .423 & 1.000 & & & & & & & & \\
\hline $\mathrm{diNH}$ & -.286 & .462 & .603 & .535 & 1.000 & & & & & & & \\
\hline diH & -.247 & .505 & .404 & .423 & .278 & 1.000 & & & & & & \\
\hline diO & -.310 & .428 & .430 & .502 & .577 & .243 & 1.000 & & & & & \\
\hline $\ln$ Pop & -.029 & .231 & -.026 & .130 & -.147 & .344 & -.135 & 1.000 & & & & \\
\hline Above 18 & -.075 & .119 & .095 & .010 & .095 & -.057 & -.068 & -.057 & 1.000 & & & \\
\hline Foreign & .267 & -.132 & .062 & -.209 & -.279 & .070 & -.333 & .152 & -.104 & 1.000 & & \\
\hline PPH & .186 & -.244 & -.129 & -.177 & -.343 & -.058 & -.170 & .076 & -.456 & .578 & 1.000 & \\
\hline CivLF & .550 & -.219 & -.219 & -.250 & -.026 & -.035 & -.128 & .098 & -.149 & .174 & .093 & 1.000 \\
\hline
\end{tabular}


Table 3.3 Correlation Matrix Median Gross Rent

\begin{tabular}{|c|c|c|c|c|c|c|c|c|c|c|c|c|}
\hline & $\begin{array}{l}\text { Med } \\
\text { Rent }\end{array}$ & $\mathrm{diB}$ & diAI & $\operatorname{diA}$ & diNH & $\mathrm{diH}$ & $\mathrm{diO}$ & $\ln$ Pop & $\begin{array}{c}\text { Above } \\
18\end{array}$ & Foreign & $\mathrm{PPH}$ & CivLF \\
\hline MedRent & 1.000 & & & & & & & & & & & \\
\hline $\mathrm{diB}$ & -.317 & 1.000 & & & & & & & & & & \\
\hline diAI & -.079 & .479 & 1.000 & & & & & & & & & \\
\hline diA & -.489 & .566 & .423 & 1.000 & & & & & & & & \\
\hline diNH & -.440 & .462 & .603 & .535 & 1.000 & & & & & & & \\
\hline $\mathrm{diH}$ & -.172 & .505 & .404 & .423 & .278 & 1.000 & & & & & & \\
\hline $\mathrm{diO}$ & -.496 & .428 & .430 & .502 & .577 & .243 & 1.000 & & & & & \\
\hline $\operatorname{lnPop}$ & .039 & .231 & -.026 & .130 & -.147 & .344 & -.135 & 1.000 & & & & \\
\hline Above18 & .022 & .119 & .095 & .010 & .095 & -.057 & -.068 & -.057 & 1.000 & & & \\
\hline Foreign & .567 & -.132 & .062 & $\begin{array}{l}-209 \\
-.29\end{array}$ & -.279 & .070 & -.333 & .152 & -.104 & 1.000 & & \\
\hline PPH & .327 & -.244 & -.129 & -.177 & -.343 & -.058 & -.170 & .076 & -.456 & .578 & 1.000 & \\
\hline CivLF & .298 & -.219 & -.219 & -.250 & -.026 & -.035 & -.128 & .098 & -.149 & .174 & .093 & 1.000 \\
\hline
\end{tabular}

Table 3.4 Correlation Matrix Health Insurance

\begin{tabular}{|l|l|l|l|l|l|l|l|l|l|l|l|l|}
\hline & $\begin{array}{c}\text { Health } \\
\text { Insur }\end{array}$ & $\mathrm{diB}$ & $\mathrm{diAI}$ & $\mathrm{diA}$ & $\mathrm{diNH}$ & $\mathrm{diH}$ & $\mathrm{diO}$ & $\mathrm{lnPop}$ & $\begin{array}{c}\text { Above } \\
18\end{array}$ & Foreign & PPH & CivLF \\
\hline HealthInsur & 1.000 & & & & & & & & & & & \\
\hline $\mathrm{diB}$ & -.251 & 1.000 & & & & & & & & & & \\
\hline $\mathrm{diAI}$ & .035 & .479 & 1.000 & & & & & & & & & \\
\hline $\mathrm{diA}$ & -.227 & .566 & .423 & 1.000 & & & & & & & & \\
\hline $\mathrm{diNH}$ & .041 & .462 & .603 & .535 & 1.000 & & & & & & & \\
\hline diH & -.271 & .505 & .404 & .423 & .278 & 1.000 & & & & & & \\
\hline diO & -.106 & .428 & .430 & .502 & .577 & .243 & 1.000 & & & & & \\
\hline $\ln$ Pop & -.142 & .231 & -.026 & .130 & -.147 & .344 & -.135 & 1.000 & & & & \\
\hline Above18 & .258 & .119 & .095 & .010 & .095 & -.057 & -.068 & -.057 & 1.000 & & & \\
\hline Foreign & -.321 & -.132 & .062 & -.209 & -.279 & .070 & -.333 & .152 & -.104 & 1.000 & & \\
\hline PPH & -.352 & -.244 & -.129 & -.177 & -.343 & -.058 & -.170 & .076 & -.456 & .578 & 1.000 & \\
\hline CivLF & .251 & -.219 & -.219 & -.250 & -.026 & -.035 & -.128 & .098 & -.149 & .174 & .093 & 1.000 \\
\hline
\end{tabular}


Table 3.5 Correlation Matrix Firms per Capita

\begin{tabular}{|c|c|c|c|c|c|c|c|c|c|c|c|c|}
\hline & $\begin{array}{c}\text { Firms } \\
\text { Cap }\end{array}$ & $\mathrm{diB}$ & diAI & $\operatorname{diA}$ & diNH & $\mathrm{diH}$ & $\mathrm{diO}$ & $\operatorname{lnPop}$ & $\begin{array}{c}\text { Above } \\
18\end{array}$ & Foreign & PPH & CivLF \\
\hline FirmsCap & 1.000 & & & & & & & & & & & \\
\hline $\mathrm{diB}$ & .058 & 1.000 & & & & & & & & & & \\
\hline diAI & .101 & .479 & 1.000 & & & & & & & & & \\
\hline $\operatorname{diA}$ & -.203 & .566 & .423 & 1.000 & & & & & & & & \\
\hline diNH & -.035 & .462 & .603 & .535 & 1.000 & & & & & & & \\
\hline $\mathrm{diH}$ & -.018 & .505 & .404 & .423 & .278 & 1.000 & & & & & & \\
\hline $\mathrm{diO}$ & -.128 & .428 & .430 & .502 & .577 & .243 & 1.000 & & & & & \\
\hline $\ln$ Pop & .026 & .231 & -.026 & .130 & -.147 & .344 & -.135 & 1.000 & & & & \\
\hline Above18 & .293 & .119 & .095 & .010 & .095 & -.057 & -.068 & -.057 & 1.000 & & & \\
\hline Foreign & .268 & -.132 & .062 & -.209 & -.279 & .070 & -.333 & .152 & -.104 & 1.000 & & \\
\hline $\mathrm{PPH}$ & -.156 & -.244 & -.129 & -.177 & -.343 & -.058 & -.170 & .076 & -.456 & .578 & 1.000 & \\
\hline CivLF & .185 & -.219 & -.219 & -.250 & -.026 & -.035 & -.128 & .098 & -.149 & .174 & .093 & 1.000 \\
\hline
\end{tabular}


Table 4.1 Regression Results Median Home Value

\begin{tabular}{|c|c|}
\hline VARIABLES & $\begin{array}{c}\text { Natural Log of Median Home Value } \\
(\ln \text { MedHome) }\end{array}$ \\
\hline Dissimilarity Index - Black (diB) & $\begin{array}{l}-0.002^{*} \\
{[0.001]}\end{array}$ \\
\hline Dissimilarity Index - American Indian (diAI) & $\begin{array}{c}0.011^{* * *} \\
{[0.001]}\end{array}$ \\
\hline Dissimilarity Index - Asian (diA) & $\begin{array}{c}-0.015^{* * *} \\
{[0.001]}\end{array}$ \\
\hline Dissimilarity Index - Native Hawaiian (diNH) & $\begin{array}{c}-0.010^{* * *} \\
{[0.001]}\end{array}$ \\
\hline Dissimilarity Index - Hispanic (diH) & $\begin{array}{l}0.002 * * \\
{[0.001]}\end{array}$ \\
\hline Dissimilarity Index - Other (diO) & $\begin{array}{c}-0.002 * * \\
{[0.001]}\end{array}$ \\
\hline Natural Log of Population (InPop) & $\begin{array}{l}-0.008 \\
{[0.017]}\end{array}$ \\
\hline Persons Above 18, Percent (Above18) & $\begin{array}{c}0.046 * * * \\
{[0.004]}\end{array}$ \\
\hline Foreign Born Persons, Percent (Foreign) & $\begin{array}{c}0.013 * * * \\
{[0.001]}\end{array}$ \\
\hline Persons Per Household (PPH) & $\begin{array}{c}0.220 * * * \\
{[0.058]}\end{array}$ \\
\hline Persons in Civilian Labor Force, Percent (CivLF) & $\begin{array}{c}0.026^{* * *} \\
{[0.002]}\end{array}$ \\
\hline Constant & $\begin{array}{c}7.158 * * * \\
{[0.527]}\end{array}$ \\
\hline Observations & 1,246 \\
\hline R-squared & 0.590 \\
\hline Root MSE & 0.396 \\
\hline $\begin{array}{l}\text { Standard errors in brackets } \\
* * * \mathrm{p}<0.01, * * \mathrm{p}<0.05, * \mathrm{p}<0.1\end{array}$ & \\
\hline
\end{tabular}


Table 4.2 Regression Results Median Income

\begin{tabular}{|c|c|}
\hline VARIABLES & $\begin{array}{c}\text { Natural Log of Median Income } \\
\text { (InMedInc) }\end{array}$ \\
\hline Dissimilarity Index - Black (diB) & $\begin{array}{c}-0.001 * * \\
{[0.001]}\end{array}$ \\
\hline Dissimilarity Index - American Indian (diAI) & $\begin{array}{c}0.006 * * * \\
{[0.001]}\end{array}$ \\
\hline Dissimilarity Index - Asian (diA) & $\begin{array}{c}-0.011 * * * \\
{[0.001]}\end{array}$ \\
\hline Dissimilarity Index - Native Hawaiian (diNH) & $\begin{array}{c}-0.003 * * * \\
{[0.001]}\end{array}$ \\
\hline Dissimilarity Index - Hispanic (diH) & $\begin{array}{c}-0.003 * * * \\
{[0.001]}\end{array}$ \\
\hline Dissimilarity Index - Other (diO) & $\begin{array}{c}-0.001 \\
{[0.001]}\end{array}$ \\
\hline Natural Log of Population (InPop) & $\begin{array}{l}-0.001 \\
{[0.010]}\end{array}$ \\
\hline Persons Above 18, Percent (Above18) & $\begin{array}{l}-0.000 \\
{[0.003]}\end{array}$ \\
\hline Foreign Born Persons, Percent (Foreign) & $\begin{array}{c}0.001 \\
{[0.001]}\end{array}$ \\
\hline Persons Per Household (PPH) & $\begin{array}{c}0.009 \\
{[0.036]}\end{array}$ \\
\hline Persons in Civilian Labor Force, Percent (CivLF) & $\begin{array}{c}0.025 * * * \\
{[0.001]}\end{array}$ \\
\hline Constant & $\begin{array}{c}-0.001 * * \\
{[0.001]}\end{array}$ \\
\hline Observations & 1,246 \\
\hline R-squared & 0.521 \\
\hline Root MSE & 0.244 \\
\hline $\begin{array}{l}\text { Standard errors in brackets } \\
* * * \mathrm{p}<0.01, * * \mathrm{p}<0.05, * \mathrm{p}<0.1\end{array}$ & \\
\hline
\end{tabular}


Table 4.3 Regression Results Median Gross Rent

\begin{tabular}{|c|c|}
\hline VARIABLES & $\begin{array}{l}\text { Median Gross Rent } \\
\text { (MedRent) }\end{array}$ \\
\hline Dissimilarity Index - Black (diB) & $\begin{array}{c}0.227 \\
{[0.576]}\end{array}$ \\
\hline Dissimilarity Index - American Indian (diAI) & $\begin{array}{c}5.845^{* * *} \\
{[0.637]}\end{array}$ \\
\hline Dissimilarity Index - Asian (diA) & $\begin{array}{c}-6.309^{* * *} \\
{[0.785]}\end{array}$ \\
\hline Dissimilarity Index - Native Hawaiian (diNH) & $\begin{array}{c}-3.999 * * * \\
{[0.499]}\end{array}$ \\
\hline Dissimilarity Index - Hispanic (diH) & $\begin{array}{c}-1.917 * * * \\
{[0.613]}\end{array}$ \\
\hline Dissimilarity Index - Other (diO) & $\begin{array}{c}-4.491 * * * \\
{[0.586]}\end{array}$ \\
\hline Natural Log of Population (InPop) & $\begin{array}{l}-14.241 \\
{[9.052]}\end{array}$ \\
\hline Persons Above 18, Percent (Above18) & $\begin{array}{c}9.384 * * * \\
{[2.238]}\end{array}$ \\
\hline Foreign Born Persons, Percent (Foreign) & $\begin{array}{c}8.096 * * * \\
{[0.786]}\end{array}$ \\
\hline Persons Per Household (PPH) & $\begin{array}{c}82.122 * * * \\
{[31.149]}\end{array}$ \\
\hline Persons in Civilian Labor Force, Percent (CivLF) & $\begin{array}{c}9.412 * * * \\
{[1.103]}\end{array}$ \\
\hline Constant & $\begin{array}{c}38.057 \\
{[281.711]}\end{array}$ \\
\hline Observations & 1,246 \\
\hline R-squared & 0.560 \\
\hline Root MSE & 211.6 \\
\hline $\begin{array}{l}\text { Standard errors in brackets } \\
* * * \mathrm{p}<0.01, * * \mathrm{p}<0.05, * \mathrm{p}<0.1\end{array}$ & \\
\hline
\end{tabular}


Table 4.4 Regression Results Health Insurance

\begin{tabular}{|c|c|}
\hline VARIABLES & $\begin{array}{c}\text { Persons with Health Insurance, Percent } \\
\text { (HealthInsur) }\end{array}$ \\
\hline Dissimilarity Index - Black (diB) & $\begin{array}{c}-0.110^{* * *} \\
{[0.014]}\end{array}$ \\
\hline Dissimilarity Index - American Indian (diAI) & $\begin{array}{c}0.176^{* * *} \\
{[0.015]}\end{array}$ \\
\hline Dissimilarity Index - Asian (diA) & $\begin{array}{c}-0.086^{* * *} \\
{[0.019]}\end{array}$ \\
\hline Dissimilarity Index - Native Hawaiian (diNH) & $\begin{array}{c}-0.003 \\
{[0.012]}\end{array}$ \\
\hline Dissimilarity Index - Hispanic (diH) & $\begin{array}{c}-0.087 * * * \\
{[0.015]}\end{array}$ \\
\hline Dissimilarity Index - Other (diO) & $\begin{array}{c}-0.070 * * * \\
{[0.014]}\end{array}$ \\
\hline Natural Log of Population (InPop) & $\begin{array}{c}0.271 \\
{[0.219]}\end{array}$ \\
\hline Persons Above 18, Percent (Above18) & $\begin{array}{c}0.246^{* * *} \\
{[0.054]}\end{array}$ \\
\hline Foreign Born Persons, Percent (Foreign) & $\begin{array}{c}-0.234 * * * \\
{[0.019]}\end{array}$ \\
\hline Persons Per Household (PPH) & $\begin{array}{c}-1.701 * * \\
{[0.753]} \\
\end{array}$ \\
\hline Persons in Civilian Labor Force, Percent (CivLF) & $\begin{array}{c}0.281 * * * \\
{[0.027]}\end{array}$ \\
\hline Constant & $\begin{array}{c}60.685^{* * *} \\
{[6.807]} \\
\end{array}$ \\
\hline Observations & 1,246 \\
\hline R-squared & 0.434 \\
\hline Root MSE & 5.112 \\
\hline $\begin{array}{l}\text { Standard errors in brackets } \\
* * * \mathrm{p}<0.01, * * \mathrm{p}<0.05, * \mathrm{p}<0.1\end{array}$ & \\
\hline
\end{tabular}


Table 4.5 Regression Results Firms per Capita

\begin{tabular}{|c|c|}
\hline VARIABLES & $\begin{array}{c}\text { Firms per Capita } \\
\text { (FirmsCap) }\end{array}$ \\
\hline Dissimilarity Index - Black (diB) & $\begin{array}{c}0.002 * * * \\
{[0.000]}\end{array}$ \\
\hline Dissimilarity Index - American Indian (diAI) & $\begin{array}{c}0.003 * * * \\
{[0.000]}\end{array}$ \\
\hline Dissimilarity Index - Asian (diA) & $\begin{array}{c}-0.004 * * * \\
{[0.000]}\end{array}$ \\
\hline Dissimilarity Index - Native Hawaiian (diNH) & $\begin{array}{l}-0.000 \\
{[0.000]}\end{array}$ \\
\hline Dissimilarity Index - Hispanic (diH) & $\begin{array}{c}-0.001 * * * \\
{[0.000]}\end{array}$ \\
\hline Dissimilarity Index - Other (diO) & $\begin{array}{c}0.000 \\
{[0.000]}\end{array}$ \\
\hline Natural Log of Population (InPop) & $\begin{array}{l}-0.000 \\
{[0.001]}\end{array}$ \\
\hline Persons Above 18, Percent (Above18) & $\begin{array}{l}0.001 * * \\
{[0.000]}\end{array}$ \\
\hline Foreign Born Persons, Percent (Foreign) & $\begin{array}{c}0.001 * * * \\
{[0.000]}\end{array}$ \\
\hline Persons Per Household (PPH) & $\begin{array}{c}-0.030^{* * *} \\
{[0.004]}\end{array}$ \\
\hline Persons in Civilian Labor Force, Percent (CivLF) & $\begin{array}{c}0.001 * * * \\
{[0.000]}\end{array}$ \\
\hline Constant & $\begin{array}{l}0.071^{*} \\
{[0.038]}\end{array}$ \\
\hline Observations & 1,246 \\
\hline R-squared & 0.865 \\
\hline Root MSE & .029 \\
\hline $\begin{array}{l}\text { Standard errors in brackets } \\
* * * \mathrm{p}<0.01, * * \mathrm{p}<0.05, * \mathrm{p}<0.1\end{array}$ & \\
\hline
\end{tabular}


A special thank you to Dr. Alan Gin, Dr. Alyson Ma, the USD Economics Department, and the USD Honors Program for their contributions to this paper. 